\title{
Prediabetes Progression to Diabetes among Veterans
}

\author{
Subhashini Yaturu \\ Section of Endocrinology, WJB Dorn VA Medical Center/Professor of Clinical Medicine, UofSC SOM, Columbia, SC, USA \\ Email: Subhashini.Yaturu@va.gov
}

How to cite this paper: Yaturu, S. (2020) Prediabetes Progression to Diabetes among Veterans. Journal of Diabetes Mellitus, 10, 202-207.

https://doi.org/10.4236/jdm.2020.103016

Received: July 2, 2020

Accepted: August 21, 2020

Published: August 24, 2020

Copyright $\odot 2020$ by author(s) and Scientific Research Publishing Inc. This work is licensed under the Creative Commons Attribution International License (CC BY 4.0).

http://creativecommons.org/licenses/by/4.0/

\begin{abstract}
Prevalence of diabetes and prediabetes, as well as cardiovascular disease is very high among Veterans. The aim of the study is to evaluate the rate of progression of prediabetes and the factors associated with progression to diabetes. This is an observational, retrospective data-base study of progression of prediabetes to diabetes at Veterans Health Administration at Columbia, South Carolina, diagnosed between 2008 and 2019 based on HbA1C (5.7 to 6.4). We calculated the time interval to progress to diabetes from the date of baseline data, and then the percentage of subjects progressed to diabetes is calculated as $1^{\text {st }}$ year, $2^{\text {nd }}$ year and so on. Statistical analysis included descriptive statistics and correlation of parameters with progression to diabetes. Subjects with prediabetes identified include 72,604 with mean age 66 and mean HbA1C of 5.9. Among the study population, only $8 \%$ were women. Association of hypertension was $55 \%$ and atherosclerotic coronary artery disease was $13 \%$. Among the study population, 10,710 subjects did not have follow up. Among 61,894 prediabetics 21,954 (35\%) progressed to diabetes, while 39,940 (65\%) remained as prediabetic. Those progressed to diabetes had relatively higher $\mathrm{HbA1C}$ and associated with higher prevalence of atherosclerotic cardiovascular disease, hypertension and are older by age. About $60 \%$ of those progressed to diabetes are within 2 years from baseline. We conclude that aggressive measures are necessary to prevent progression to diabetes to decrease the morbidity associated with diabetes and health care burden. It is essential to identify those progress to diabetes, such as biomarker evaluation.
\end{abstract}

\section{Keywords}

Diabetes, Prediabetes, Progression to Diabetes, Hemoglobin A1C

\section{Background}

Prevalence of type 2 diabetes among Veterans is $>25 \%$, compared to that of gen- 
eral population. In US, 84.1 million adults have prediabetes (33.9\% population). Among them 23.1 million adults are aged 65 or older. Prediabetes is an intermediate condition with blood glucose levels just above normoglycemia and diabetes, have a higher risk of developing T2DM and associated pathophysiology. The diagnostic criteria for diabetes according to American Diabetes Association (ADA) include impaired fasting glucose (IFG) with fasting glucose between 100 and 125; impaired glucose tolerance (IGT) with 2-hour post prandial glucose between $140-199 \mathrm{mg} / \mathrm{dl}(7.8-11.0 \mathrm{mmol} / \mathrm{l})$ or hemoglobin A1C (HbA1C) between 5.7 and 6.4. Prediabetes is increasingly prevalent and is associated with adverse cardiovascular risk, in addition to be high risk of progression to diabetes. Framingham study noted that individuals with early-onset prediabetes, despite lifelong avoidance of overt diabetes, had greater propensity for death due to cardiovascular or coronary versus non-cardiovascular disease compared with those who maintained lifelong normal glucose status [1]. Obesity and overweight are high among Veterans with obesity rates of $41 \%$ and overweight of $37 \%$. The primary objectives of this study were to evaluate the rate of progression of prediabetes to diabetes and associated conditions and or risk factors for that.

\section{Methods}

Design: Single center, retrospective study done at William Jennings Bryan Dorn Veteran Hospital in Columbia SC. This study of prediabetes (hemoglobin A1C between 5.7 and 6.4) progression to diabetes, included all available subjects with prediabetes between January 2008 to June 2019 with exclusion of subjects with diabetes with low HbA1C and on glucose lowering medications for diabetes. The data for this study was collected utilizing computerized patient record system (CPRS) based on hemoglobin A1C who qualifies for prediabetes and without a diagnosis of diabetes, after approval by institutional review board (IRB) as well as research and development board.

\section{Statistical Analysis}

Data are expressed as mean \pm SD (standard deviation). Continuous variables were compared using Student's $t$ test. Statistical significance was considered at $p$ $<0.05$. The rate of progression to diabetes was carried out for each follow up year.

\section{Results}

Data was available for 72,604 subjects. Among them 10,710 subjects did not have follow up $\mathrm{HbA1C}$ or other labs. The baseline data of all subjects is shown in Table 1. Follow-up data is available for 61,894 subjects. Among those who had follow up, 21,954 (35\%) progressed to diabetes, while 39,940 (65\%) remained as prediabetic. The comparative data of those progressed and who did not progress is shown in Table 2. Time interval for progression was at a mean of 831 days 
with range of 90 days to 3727 days. Most of those progressed to diabetes (about $60 \%$ of those progressed) are within 2 years from baseline as shown in Graph 1 . The mean age of subjects who progressed to diabetes is 69 with HbA1C of 6.15 compared to the mean age of 66 in those who did not progress. Progression to diabetes negatively correlated with $\operatorname{HbA1C}(r=0.34 ; p<0.001)$. Associated other risks include VMI, hypertension and atherosclerotic cardiovascular disease as shown in Table 3.

Table 1. Baseline data of all subjects with prediabetes.

\begin{tabular}{cc} 
Total number & 72,604 \\
Age & $66 \pm 14$ \\
BMI & $32 \pm 2.6$ \\
HbA1C & $5.9 \pm 1.1$ \\
HTN (\%) & 55 \\
ASCVD (\%) & 13 \\
Hyperlipidemia/meds (\%) & 55 \\
\hline
\end{tabular}

HTN: hypertension; ASCVD: atherosclerotic cardiovascular disease; BMI: Body mass index $\left(\mathrm{kg} / \mathrm{m}^{2}\right)$.

Table 2. Comparison between those who progressed to diabetes and not progressed to diabetes.

\begin{tabular}{cccc}
\hline & Prog to DM & No. prog to DM & $p$ Value \\
\hline No. & 21,954 & 39,940 & $<0.01$ \\
Age & 69 & 65 & $<0.01$ \\
HTN \% & 79 & 54 & $<0.01$ \\
CAD\% & 21 & 10 & $<0.01$ \\
HbA1C & 6.15 & 5.9 & $<0.01$ \\
\hline
\end{tabular}

HTN: hypertension; ASCVD: atherosclerotic cardiovascular disease; BMI: Body mass index $\left(\mathrm{kg} / \mathrm{m}^{2}\right)$.

\% Subjects progressed by Follow up years

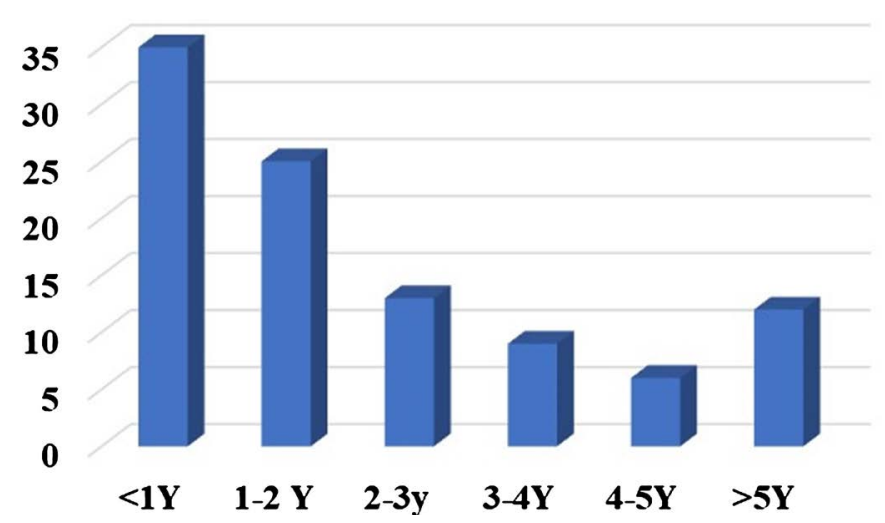

Graph 1. Showing percentage of subjects progressed to diabetes from baseline. 
Table 3. Rate of progression of prediabetes to diabetes from baseline.

\begin{tabular}{cccccc}
\hline & \% Sub & Mean A1C & Mean age & HTN (\%) & ASCVD (\%) \\
\hline $1^{\text {st }}$ Year & 35 & 6.23 & 70.3 & 81 & 22 \\
$2^{\text {nd }}$ Year & 25 & 6.17 & 69.4 & 78 & 18 \\
$3^{\text {rd }}$ Year & 13 & 6.12 & 69.2 & 78 & 16 \\
$4^{\text {th }}$ Year & 9 & 6.1 & 68.4 & 71 & 13 \\
$5^{\text {th }}$ Year & 6 & 6.07 & 68.7 & 70 & 13 \\
$>5$ Years & 12 & 6.02 & 67.5 & 73 & 12 \\
\hline
\end{tabular}

$\%$ sub: Percentage of subjects progressed to diabetes; HTN: Hypertension; ASCVD: atherosclerotic Cardiovascular disease.

\section{Discussion}

In this study, we noted prevalence of prediabetes among Veterans is around 23\% - 27\%. Diabetes is $>25 \%$ among Veterans. Obesity is a high-risk factor for insulin resistance. Obesity and overweight are high among Veterans with obesity rates of $41 \%$ and overweight of $37 \%$. In this study, most of the prediabetics are obese. The first interesting finding is negative correlation with $\mathrm{HbA1C}$ with the rate of progression. Weight loss strategies with significant improvements in weight had decreased rates of progression to diabetes [2] [3]. The next interesting finding is that higher rate of progression to diabetes was associated with higher prevalence of hypertension. Similar to our data, a cost analysis study of prediabetes reported that presence of hypertension substantially increased health care costs and likelihood of progression to diabetes [4]. Those who progressed early had high rates of hypertension and atherosclerotic cardiovascular disease. Our data is similar to the reported data that indicated elevated cardiovascular risk in subjects with prediabetes and hypertension (odds ratio, 2.41; 95\% confidence interval, 1.25 - 4.64) [5].

In meta-analysis, as well as prospective studies, it is reported that lifestyle intervention was shown safe, cost effective and efficacious to prevent progression $\mathrm{n}$ to diabetes [6] [7] [8] [9]. Similarly increasing physical activity said to decrease the rate of progression. [10] [11]. In Framingham study, it is reported that Individuals with early-onset prediabetes ( $<50$ years of age), despite lifelong avoidance of overt diabetes, had greater propensity for death due to cardiovascular or coronary versus non-cardiovascular disease compared with those who maintained lifelong normal glucose status [1]. Vitamin D deficiency association noted in prediabetes progression [12] [13]. In a recent clinical trial, Vitamin D supplementation did not decrease progression to diabetes [14]. In my opinion, those comorbid conditions in prediabetics lead to Vitamin D deficiency and hence did not make much difference in rate of progression with supplementation.

\section{Conclusion}

Prediabetics with HbA1C at or more than 6 need extra attention to prevent progression to diabetes. While the threat of the rising prevalence of diabetes and its 
attendant costs increases, all that can be done to prevent diabetes should be done with urgency. Similarly, associated comorbid conditions should be addressed to prevent cardiovascular morbidity and mortality.

\section{Limitations}

Since it is a retrospective study, two-hour post prandial glucoses are not available to correlate with progression. Second limitation is limited information on family history of diabetes. Third is lack of lifestyle information.

\section{Acknowledgements}

The author receives salary support from Veterans Health Administration. Appreciate Phillips Mullinax for data retrieval. This study data is the result of work supported with resources and the use of facilities at the Dorn VAMC at Columbia, SC, United States.

\section{Conflicts of Interest}

The author declares no conflicts of interest regarding the publication of this paper.

\section{References}

[1] Echouffo-Tcheugui, J.B., Niiranen, T.J., McCabe, E.L., Jain, M., Vasan, R.S., Larson, M.G., et al. (2018) Lifetime Prevalence and Prognosis of Prediabetes without Progression to Diabetes. Diabetes Care, 41, e117-e118. https://doi.org/10.2337/dc18-0524

[2] Norris, S.L., Zhang, X.P., Avenell, A., Gregg, E., Bowman, B., Schmid, C.H., et al. (2005) Long-Term Effectiveness of Weight-Loss Interventions in Adults with Pre-Diabetes: A Review. American Journal of Preventive Medicine, 28, 126-139. https://doi.org/10.1016/j.amepre.2004.08.006

[3] Norris, S.L., Zhang, X.P., Avenell, A., Gregg, E., Bowman, B., et al. (2004) Long-Term Effectiveness of Lifestyle and Behavioral Weight Loss Interventions in Adults with Type 2 Diabetes: A Meta-Analysis. The American Journal of Medicine, 117, 762-774. https://doi.org/10.1016/j.amjmed.2004.05.024

[4] Francis, B.H., Song, X., Andrews, L.M., Purkayastha, D., Princic, N., Sedgley, R., et al. (2011) Progression to Type 2 Diabetes, Healthcare Utilization, and Cost among Pre-Diabetic Patients with or without Comorbid Hypertension. Current Medical Research and Opinion, 27, 809-819. https://doi.org/10.1185/03007995.2011.554806

[5] Qiu, M.Y., Shen, W.L., Song, X.M., Ju, L.P., Tong, W.X., Wang, H.Y., et al. (2015) Effects of Prediabetes Mellitus Alone or Plus Hypertension on Subsequent Occurrence of Cardiovascular Disease and Diabetes Mellitus: Longitudinal Study. Hypertension, 65, 525-530. https://doi.org/10.1161/HYPERTENSIONAHA.114.04632

[6] Glechner, A., Keuchel, L., Affengruber, L., Titscher, V., Sommer, I., Matyas, N., et al. (2018) Effects of Lifestyle Changes on Adults with Prediabetes: A Systematic Review and Meta-Analysis. Prim Care Diabetes, 12, 393-408.

https://doi.org/10.1016/j.pcd.2018.07.003

[7] Barry, E., Greenhalgh, T. and Fahy, N. (2018) How Are Health-Related Behaviours Influenced by a Diagnosis of Pre-Diabetes? A Meta-Narrative Review. BMC Medicine, 16, 121. https://doi.org/10.1186/s12916-018-1107-6 
[8] Jiang, L., Johnson, A., Pratte, K., Beals, J., Bullock, A., Manson, S.M., et al. (2018) Long-Term Outcomes of Lifestyle Intervention to Prevent Diabetes in American Indian and Alaska Native Communities: The Special Diabetes Program for Indians Diabetes Prevention Program. Diabetes Care, 41,1462-1470. https://doi.org/10.2337/dc17-2685

[9] Kosaka, K., Noda, M. and Kuzuya, T. (2005) Prevention of Type 2 Diabetes by Lifestyle Intervention: A Japanese Trial in IGT Males. Diabetes Research and Clinical Practice, 67, 152-162. https://doi.org/10.1016/j.diabres.2004.06.010

[10] Jadhav, R.A., Hazari, A., Monterio, A., Kumarm S. and Maiyam, A.G. (2017) Effect of Physical Activity Intervention in Prediabetes: A Systematic Review with Meta-Analysis. Journal of Physical Activity and Health, 14, 745-755. https://doi.org/10.1123/jpah.2016-0632

[11] Wu, T., Gao, X., Chen, M. and Van Dam, R.M. (2009) Long-Term Effectiveness of Diet-Plus-Exercise Interventions vs. Diet-Only Interventions for Weight Loss: A Meta-Analysis. Obesity Reviews, 10, 313-323.

https://doi.org/10.1111/j.1467-789X.2008.00547.x

[12] Lu, L., Bennett, D.A., Millwood, I.Y., Parish, S., McCarthy, M.I., Mahajan, A., et al. (2018) Association of Vitamin D with Risk of Type 2 Diabetes: A Mendelian Randomisation Study in European and Chinese Adults. PLoS Medicine, 15, e1002566. https://doi.org/10.1371/journal.pmed.1002566

[13] Pittas, A.G., Lau, J., Hu, F.B. and Dawson-Hughes, B. (2007) The Role of Vitamin D and Calcium in Type 2 Diabetes: A Systematic Review and Meta-Analysis. The Journal of Clinical Endocrinology \& Metabolism, 92, 2017-2029. https://doi.org/10.1210/jc.2007-0298

[14] Pittas, A.G., Dawson-Hughes, B., Sheehan, P., et al. (2019) Vitamin D Supplementation and Prevention of Type 2 Diabetes. The New England Journal of Medicine, 381, 520-530. https://doi.org/10.1056/NEJMoa1900906 